\title{
Computation of scattering and radiation from open-ended waveguides and small horns
}

frandsen, $A$

Published in:

Antennas and Propagation Society International Symposium

Publication date:

1979

Document Version

Publisher's PDF, also known as Version of record

Link back to DTU Orbit

Citation (APA):

frandsen, A. (1979). Computation of scattering and radiation from open-ended waveguides and small horns. In Antennas and Propagation Society International Symposium (pp. 360-363). IEEE.

\section{General rights}

Copyright and moral rights for the publications made accessible in the public portal are retained by the authors and/or other copyright owners and it is a condition of accessing publications that users recognise and abide by the legal requirements associated with these rights.

- Users may download and print one copy of any publication from the public portal for the purpose of private study or research.

- You may not further distribute the material or use it for any profit-making activity or commercial gain

- You may freely distribute the URL identifying the publication in the public portal

If you believe that this document breaches copyright please contact us providing details, and we will remove access to the work immediately and investigate your claim. 


\section{COMPUTATION OF SCATTERING AND RADIATION FROM OPEN-ENDED WAVEGUIDES AND SMALL HORNS}

\section{A. Frandsen}

Electromagnetics Institute, Technical University of Denmark

Introduction. In spherical near-field (SNF) measurements as well as in paraboloidal reflector antenna systems, the conical horn and open waveguide antenna is an important part of the system, whether being used as a measuring probe or as a feed element. In both cases the radiation and scattering properties of the horn are of interest. With a knowledge of the radiation pattern, the spherical mode expansion coefficients, necessary for the probe-corrected SNF-transformation, can be evaluated [1]. Further, aperture illumination and efficiency of reflector antennas are derived from the radiation pattern of the feed. As the theory behind the SNF-technique does not take multiple scattering between test-antenna and probe into account, it is important to obtain a knowledge of the scattering properties, as reflections from the probe could introduce errors. In reflector antennas, scattering from the feed might be used to study the effect of aperture blockage on the radiation pattern.

The objective of this paper is to present a numerical approach to the determination of the scattering and radiation characteristics of antennas, with special emphasis on rotationally symetric structures.

Theory. We consider an arbitrary, lossless and reciprocal antenna, illuminated by an incident electromagnetic field. Defining the scattered field as the difference between the total field with the antenna present and the undisturbed incident field, it can be shown [2] that the scattered field from an antenna with an arbitrary load impedance is given by

$$
\bar{E}^{\mathrm{sc}}\left(\Gamma_{L^{\prime}}, \theta, \phi\right)=\frac{\Gamma_{L}}{1-S_{o o} \Gamma_{I}} \cdot \bar{E}_{o}^{s}(\theta, \phi)+\bar{E}_{\alpha}^{s}(\theta, \phi)
$$

Here $\Gamma_{I}$ and $s_{\infty 0}$ are the load-reflection coefficient and antenna-reflection coefficient, respectively. $(\theta, \phi)$ are the usual spherical coordinates. The first term on the right-hand-side is the re-radiated field, i.e. the field received by the antenna, reflected from the load and transmitted according to the radiation properties. The pattern of $\overline{\mathrm{E}}_{\mathrm{s}}$ is therefore the radiation pattern of the antenna. The second term is the scattered field when the antenna is matched $\left(\Gamma_{L}=0\right)$, in which case there is no re-radiation. This field $\left(\bar{E}_{d}^{s}\right)$ may be considered to consist of two contributions, namely the field the antenna will scatter in order to absorb power from the incident field, and a field due to unloaded currents on the antenna structure, i.e. currents which do not couple power to the load, but radiate. If we know $\bar{E} C^{2}(T, \theta, \phi)$ for three values of $\Gamma_{I}$ we are able to compute $S_{\infty} \cdot \bar{E}^{S}(\theta, \phi)$ and $\bar{L}_{d}^{\prime}(\theta, \phi)$, which in turn allows the determination of commonly encountered antenna characteristics. The basis for the calculations will be purely numerical and restricted to rotationally symmetric antennas, illuminated with an axially incident plane wave. In order to solve eq. (1) for the three unknowns $S_{\infty}, \bar{E}_{0}(\theta, \phi)$ and

This work was supported in part by NATO Research Crant No. 1584 CH1456-3/79/0000-0360\$00.75 (C) 1979 IEEE. 
$\overline{\mathbf{E}}_{\mathrm{S}}^{\mathrm{S}}(\theta, \phi)$ we need three equations which can be obtained by varying $\Gamma_{L}$. AS the moment-method computer program [3] used to calculate

$\bar{E}^{\mathrm{SC}}(\Gamma, \theta, \phi)$ can only handle perfectly conducting bodies of revolution, this can be achieved by varying the position of a short. Fig. 1 shows the model for the numerical calculations.

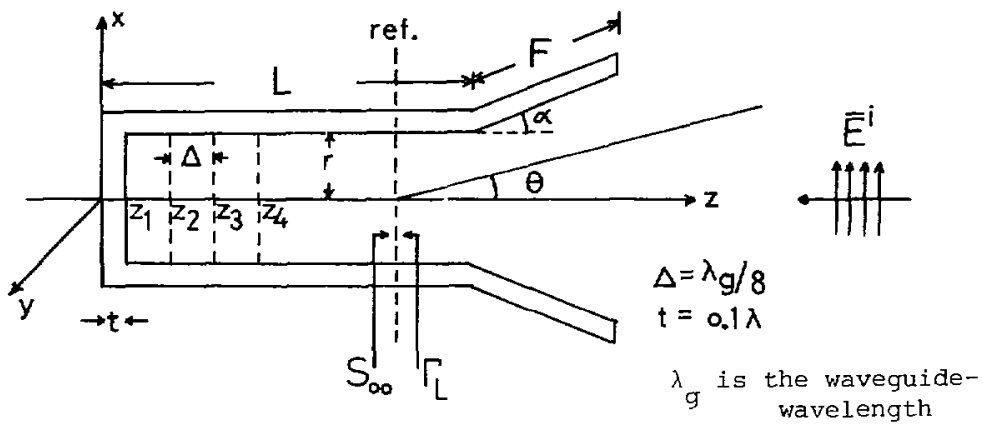

Figure 1. Model used in the calculations.

As a check on the accuracy of the calculations, the scattered field $\overline{\mathrm{E}}^{\mathrm{SC}}\left(\Gamma_{I}, \theta, \phi\right)$ is calculated for four different positions of the short $\left(z_{1}, \ldots, z_{4}\right.$, cf. fig. 1), thus enabling us to solve 4 x (3 nonlinear eqs. with 3 unknowns) and get four independent solutions to the same variable. Of course, they should be identical so that differences are a measure of the accuracy of the calculations. From the solution it is now straightforward to calculate various antenna characteristics. The on-axis gain can be shown to be

$$
G=4 \pi \cdot \frac{R}{\lambda} \cdot \frac{\left|\bar{E}_{0}(\theta=0)\right|}{\left|\bar{E}^{i}\right|} \cdot \frac{1}{1-\left.{ }^{\prime} S_{o o}\right|^{2}}
$$

where $R$ is the radius of the far-field sohere. The scattering cross -section for the matched antenna is found from

$$
\sigma_{\mathrm{sc}, \mathrm{m}}=4 \pi \cdot \mathrm{R}^{2} \cdot \frac{\left|\overline{\mathrm{E}}_{\mathrm{d}}^{\mathrm{s}}\right|^{2}}{\left|\overline{\mathrm{E}}^{\mathrm{i}}\right|^{2}}
$$

Results. Numerical calculations have been performed for an open circular waveguide and a conical horn. Table I and II summarize some of the results. Where possible, comparison with available theoretical and/or experimental data is given. The numbers are the mean-values obtained from the four solutions to eq. (1), the standard-deviations being in the range $0.1-1 \%$. $A_{p}$ is the physical area of the aperture, i.e. the area within the $\mathrm{p}^{\mathrm{i}}$ orn outer rim. 


\begin{tabular}{|c|c|c|c|c|c|c|}
\hline & \multirow[b]{2}{*}{$\begin{array}{r}\text { Gain } \\
\text { (aBi) }\end{array}$} & \multirow[b]{2}{*}{$\left|s_{\infty o}\right|$} & \multicolumn{2}{|c|}{$\begin{array}{c}12 \mathrm{~dB} \\
\text { half-beamwidth }\end{array}$} & \multirow{2}{*}{$\begin{array}{c}\text { Peak cross- } \\
\text { pol.level } \\
\text { (äB) }\end{array}$} & \multirow[b]{2}{*}{$\sigma_{s c, m} / A_{p}$} \\
\hline & & & $\begin{array}{c}\text { E-plane } \\
\text { deg }\end{array}$ & $\begin{array}{c}\text { H-plane } \\
\text { deg }\end{array}$ & & \\
\hline This work & 8.47 & 0.134 & 81.4 & 74.2 & -26.4 & 0.976 \\
\hline Theory/ & & $|4|$ & $\lfloor 5 \mid$ & {$[5]$} & {$[5]$} & \\
\hline experiment & - & 20.14 & 230 & $\eta 72$ & $v-25$ & - \\
\hline
\end{tabular}

Table I. Results for open waveguide $\mathrm{L}=2.5 \lambda, \quad \mathbf{r}=0.35 \lambda, \quad \mathrm{F}=0, \quad \alpha=0$.

\begin{tabular}{|l|l|l|l|l|l|l|} 
& & & & & & \\
\hline This work & 12.92 & 0.026 & 37.8 & 47.6 & -21.4 & 4.78 \\
\hline
\end{tabular}

Table II. Results for conical horn

$\mathrm{L}=1.6 \lambda, \quad \mathbf{r}=0.375 \lambda, \quad \mathrm{F}=1 \lambda, \quad \alpha=20 \mathrm{deg}$.

Fig. 2 shows further results for the horn in table II. The four solutions (four curves on each plot!) are seen to agree well, as the curves are nearly coincident for all $\theta$-values. Although the cross-polarization is difficult to calculate accurately in the main-beam, as it is the difference between almost equal numbers, it is seen to be very well behaved, indicating an accurate solution of eq. (1).

Conclusions. A numerical technique to predict scattering and radiation from antennas is presented. The method allows the de-. termination of radiation patterns, antenna reflection coefficient and scattering with an arbitrary load impedance. The problems of modelling feed-arrangement and load-impedance are avoided in this method.

\section{References}

[1]. Frank Jensen, "On the Probe Compensation for Near-Field Measurements on a Sphere", AEÜ, Band 29, 1975, pp. 305-308.

[2]. R.E. Collin and F.J. Zucker, "Antenna Theory", Part I, ch. 4, McGraw-Hill, 1979.

[3]. Ole Rydahl, "Application of the Theory of Characteristic Modes to Antenna Optimization", Ph.D. thesis, LD 35, Electromagnetics Institute, Technical University of Denmark (to be published).

[4]. I.A. Weinstein, "The Theory of Diffraction", Golem Press, 1969.

[5]. G.I. James and K.J. Green, "Effect of Wall Thickness on Radiation from Circular Waveguides", Elec. Letters, Vol. 14, No. 4, Pp. 90-91, 1978. 


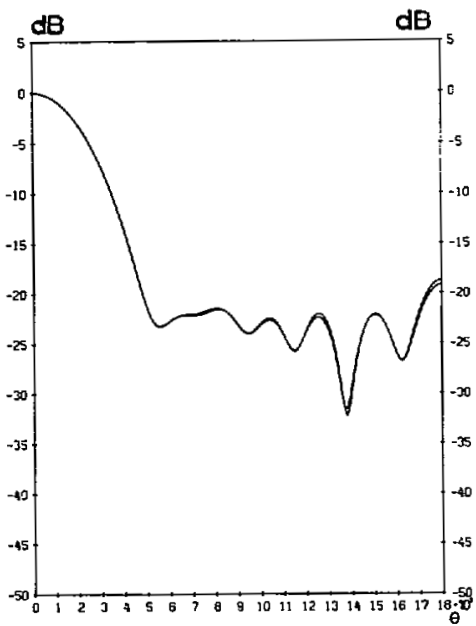

a.

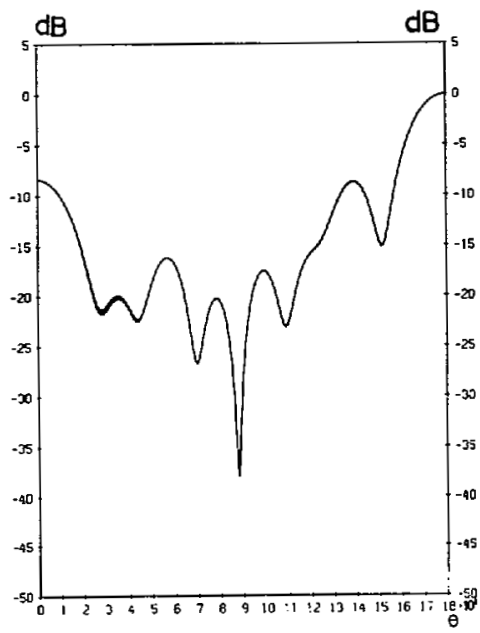

c.

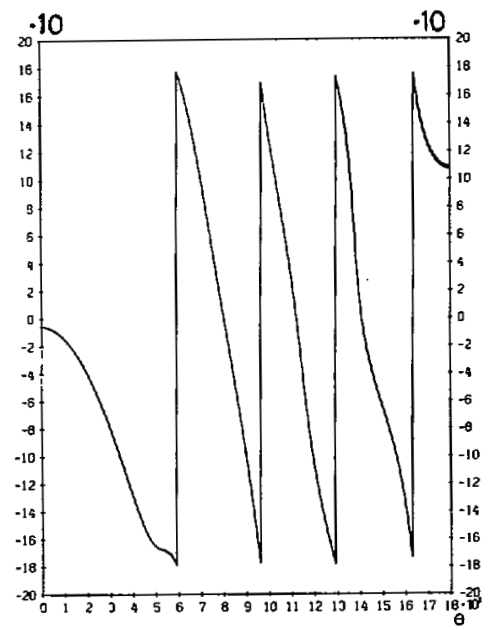

b.

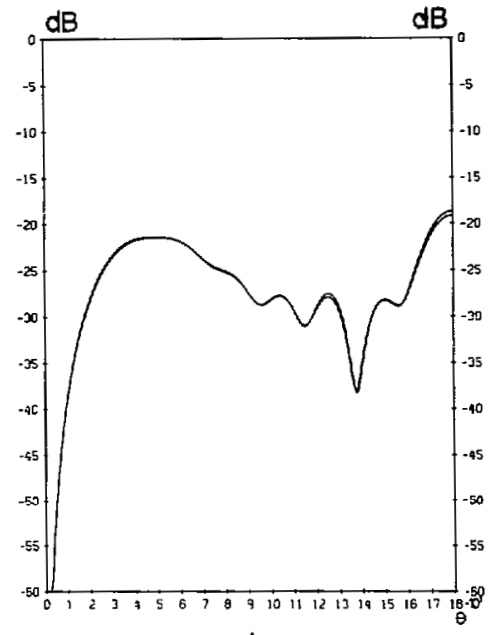

d.

Figure 2. Results for the horn in table II.
a. E-plane amplitude pattern $(\mathrm{dB})$
b. E-plane phase pattern (deg.)
c. E-plane scattering pattern $\left(\Gamma_{L}=0\right)(d B)$
a. Cross-polarization in $\phi=45 \mathrm{deg}$. plane (AB) 